\title{
Assessment of Maxillary Third Molar Status Before and After Orthodontic Treatment in Adolescent Patients
}

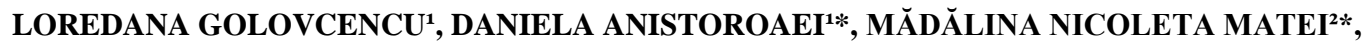 \\ GEORGETA ZEGAN ${ }^{*}$, CATALINA IULIA SAVEANU ${ }^{1}$ \\ ${ }^{1}$ Grigore T. Popa University of Medicine and Pharmacy Iasi, Faculty of Dental Medicine, Department of Surgery, \\ 16 Universitatii Str., 700115, Iasi, Romania \\ ${ }^{2}$ Dunarea de Jos University of Galati, Faculty of Medicine and Pharmacy, Galati, Romania
}

Third maxillary molar prediction for impaction and eruption should be part of the orthodontic treatment planning. In our study we evaluated the reliability of some linear and angular measurements used for the assessment of maxillary third molar status by comparing them before and after orthodontic treatment. 208 upper third molars were analyzed, 148 at patients who undergone non extraction orthodontic treatment and 60 at patients where first premolar extractions were performed. We analyzed on orthopantomograms taken at the beginning and at the end of the orthodontic the ratio between the dimension of the retromolar space and the mesio distal diameter of the third molar, the angle between the long axis of third molar and the occlusal plane and the angle between the long axis of the second and third maxillary molars. We found significant changes in retromolar space dimension after orthodontic treatment with premolars removal and slight average increase in the non extraction group. We didn't find significant statistical differences before and after orthodontic treatment neither between the angulations of the maxillary third molar with the occlusal plane, nor with the second upper molar $(p>0.05)$ in both groups. The conclusion is that the type of orthodontic treatment has little or no influence upon third molar angulation and this parameter can be used as a predictive factor for third molar status from the beginning of the orthodontic treatment.

Keywords: third maxillary molar; retromolar space; angulation

The development of the maxillary third molars and their influence on the dental arches and occlusion is a matter of concern for dentists, orthodontists and dental surgeons. The third molar is by far the tooth with the highest rate of impaction compared to any other tooth because in the modern humans the jaws and the dental arches are shorter and sometimes there is not sufficient space in the posterior area for proper eruption. The impaction of the third molar in the maxilla is less frequent than in the mandible and it is due to insufficient compensatory periosteal apposition at the posterior outline of the maxillary tuberosity [1]. This remodeling process in the distal area depends on the tooth dimension and is greater in subjects with anterior translation of the maxillary dentition during sutural growth. Bjork studies with implants in the maxillary jaw showed that the retromolar space is increased in subjects with anterior growth rotation of the maxilla, for example in class II malocclusions [2,3]. During the initial stages of development all the maxillary third molars exhibit distal angulation and they continue roots formation in the same time with pre-eruptive rotational movements through a more upright position. If the pre-eruptive rotational movements of the upper third molar bud when it comes in contact with the second molar are not sufficient for tooth uprighting or there is a lack of posterior space, the maxillary third molar may remain in distal impaction[4]. Some of the maxillary third molars present even in early stages a more mesial angulation which may lead to overuprighting and mesial impaction, which represent $12 \%$ of the total number of impactions [5].

Third maxillary molar status can be influenced by the type of orthodontic treatment [6,7]. The development of new orthodontic techniques allows "en mass" distalization of the maxillary lateral teeth in order to alleviate anterior crowding; these appliances may interfere with the normal mesial rotational movements of the tooth by distal tipping of the second molars or they even violate the posterior available space in which the upper third molar was supposed to erupt [8]. On the other hand, premolar extraction by orthodontic reasons allows mesial movement of the first and second upper molars in those cases in which maximum anchorage is not required and creates space conditions for maxillary third molar eruption $[9,10]$.

*emailanistoroaei_daniela@yahoo.com; madalinanmatei@yahoo.co.uk; georgetazegan@yahoo.com 
Maxillary third molar prognosis is difficult to be assessed at teenagers at the beginning of the orthodontic treatment because it is usually at this age in early stages of development, but is important for the judgment of the treatment plan to know whether or how the tooth is going to evolve[11,12]. In our evaluation we have to keep in mind that the changes in position and angulation will happen no matter if we extract or not the upper premolars [13-15]. This is the reason for which we studied maxillary third molars changes in a group of adolescent orthodontic patients who undergone orthodontic treatment, with or without premolar extraction and we checked if the initial prognosis for eruption or impaction remained the same at the end of the treatment. Our research wants to be an useful tool not only for orthodontists, but also for surgeons and dental practitioners in treatment planning where the third maxillary molars are involved[16,17].

\section{Experimental part}

\section{Materials and methods}

A sample of 104 patients, 62 girls(59,61\%) and 42 boys(40,38\%), aged between 12-18 years (mean age 13.65) who had undergone orthodontic treatment in the Department of Orthodontics and Dentofacial Orthopedics, University of Medicine and Pharmacy "Grigore T.Popa" Iasi, Romania were selected for this study; the total number of maxillary third molars examined in this study was 208 .

For all subjects were taken orthopantomograms before (T1) and after orthodontic treatment (T2) with the same radiologic device Pax I 3D Green (Vatech) and the assessment of third maxillary molar was performed using the software EZ 3D Plus Professional version 1.2.6.23.

74 patients had non extraction orthodontic treatment, while 30 patients had removal of both upper first premolars for orthodontic reasons. The average treatment time was 2.23 years; Angle class I, II and III malocclusions were present in $51.7 \%, 31.7 \%$ and $16.7 \%$ of the sample, respectively. Independent t-test and Chi-square test revealed no significant difference in age or in distribution of Angle class between the non extraction and extraction group ( $\mathrm{P}>0.05)$.

Exclusion criteria

-agenesis of maxillary third molars or early stages of development

-absence of the maxillary second molars

-supernumerary teeth, missing or impaction of other teeth except the third molar

-trauma, previous orthodontic treatments

-low quality orthopantomograms with distortions or errors of magnification

- the use of orthodontic mechanics for distalization of maxillary teeth.

Third maxillary molars prediction for eruption or impaction was assessed on orthopantomography by measuring the available posterior space from the distal face of the second upper molars to the projection of the pterygoid apophysis and the mesiodistal diameter of the third molar. For younger patients we added growth expectation of $1 \mathrm{~mm} /$ year up to 15 years for girls and up to 17 years for boys. The ratio (rU) between the available posterior space and the mesiodistal diameter of the maxillary molar was calculated; we considered favorable condition for eruption a ratio greater than 1 (rU>1), uncertain prognosis for $\mathrm{rU}=1$ and high risk for impaction $\mathrm{rU}<1$. Considering this measurement, the molars taken into study were divided between these three groups:rU $<1 ; \mathrm{rU}=1 ; \mathrm{rU}>1$.

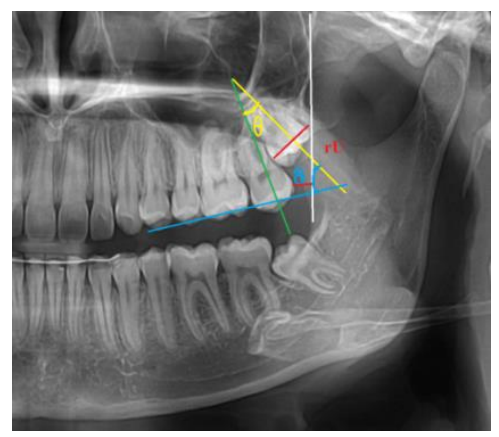

Fig.1. Measurements recorded for each third maxillary molar on orthopantomograms: rU, angle $\delta$ and angle $\theta$

Third maxillary molar angulation at the beginning and at the end of the orthodontic treatment was assessed by two angular measurements: the angle between the long axis of the upper third molar and the occlusal plane(angle $\delta)$ and the angle between the long axes of the maxillary third and second molar (angle $\theta$ )(fig.1).

The parents of all subjects signed an informed consent in accordance with the Declaration of Helsinki- Ethical Principles for Medical Research Involving Human Subjects. 


\section{Data analysis}

All analyses were carried out using SPSS 20.0 for Windows (Armonk, NY, USA). The statistical evaluation of our data was obtained by descriptive statistics and Paired Samples T-test in order to compare variables between groups; all values less than 0.05 were considered to be statistically significant.

\section{Results and discussions}

The ratio between the maxillary available posterior space and the mesiodistal diameter of the third molar

Data collected in table 1 and represented in figure 2 and figure 3 show the distribution of values for the ratio between the available posterior space and the mesiodistal diameter (rU) before ( T1) and after(T2) orthodontic treatment according to each category: : $r U<1 ; r U=1 ; r U>1$.

Table 1

DISTRIBUTION OF CASES DEPENDING ON ru VARIABLE IN THE EXTRACTION AND NON EXTRACTION GROUP

\begin{tabular}{|c|c|c|c|c|c|}
\hline & & \multicolumn{3}{|c|}{$\mathrm{rU}$ at $\mathrm{T} 1$ and $\mathrm{T} 2$} & \multirow[t]{2}{*}{ Total } \\
\hline & & $<1$ & $=1$ & $>1$ & \\
\hline \multirow{4}{*}{$\begin{array}{l}\text { Without } \\
\text { extractions }\end{array}$} & \multirow[t]{2}{*}{$\mathrm{T} 1$} & 76 & 24 & 48 & 148 \\
\hline & & $51.4 \%$ & $16.2 \%$ & $32.4 \%$ & $100.0 \%$ \\
\hline & \multirow[t]{2}{*}{$\mathrm{T} 2$} & 68 & 22 & 58 & 148 \\
\hline & & $45.9 \%$ & $14.9 \%$ & $39.2 \%$ & $100.0 \%$ \\
\hline \multirow{4}{*}{$\begin{array}{l}\text { With premolar } \\
\text { extractions }\end{array}$} & \multirow[t]{2}{*}{$\mathrm{T} 1$} & 34 & 12 & 14 & 60 \\
\hline & & $56.7 \%$ & $20.0 \%$ & $23.3 \%$ & $100.0 \%$ \\
\hline & \multirow[t]{2}{*}{$\mathrm{T} 2$} & 8 & 6 & 46 & 60 \\
\hline & & $13.3 \%$ & $10.0 \%$ & $76.7 \%$ & $100.0 \%$ \\
\hline
\end{tabular}

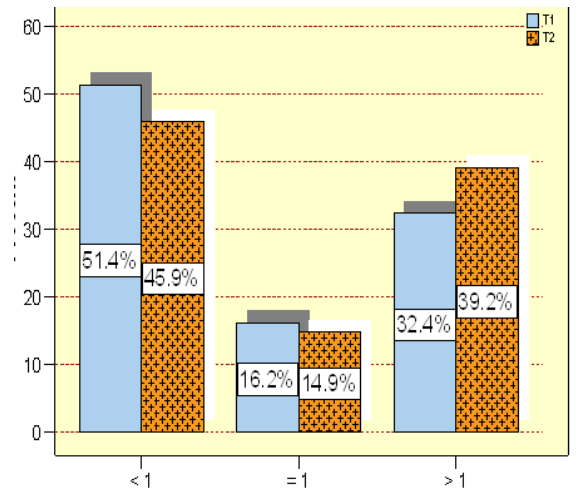

Fig 2 .rU ratio in the non extraction group before at $\mathrm{T} 1$ and $\mathrm{T} 2$

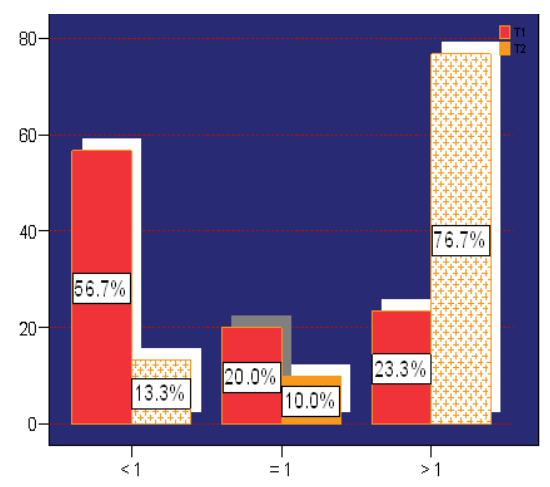

Fig.3. rU ratio in the extraction group at $\mathrm{T} 1$ and $\mathrm{T} 2$

In table 1 our study revealed the fact that in the non extraction group the number of cases from each category of values for $\mathrm{rU}$ ratio remained approximately the same before and after orthodontic treatment, which means that the initial prognostic for third maxillary available space can be used as a reliable measurement. Teeth movements during orthodontic treatment are not enough to create space in those cases in which there is a lack of space at the beginning of the treatment (in $r U<1$ the percent of cases with high probability of impaction decreased during treatment with only 5.5\%), while in rU>1 group the number of cases with good chances for eruption increased with only 5.8\%. The situation changes dramatically in the extraction group (fig.3), where there is a great decrease in the number of upper third molars with high risk of impaction ( $\mathrm{rU}<1$ group) from $56.7 \%$ to $13.3 \%$. As we expected, the number of molars in favorable condition for eruption from the point of view of available space ( $\mathrm{rU}>1)$ increased for 3.5 times at the end of the orthodontic treatment with bilateral first premolar removal. In these extractional cases the available posterior space and $\mathrm{rU}$ ratio are not recommended to be used as a prediction indicator for maxillary third molar eruption or impaction.

The angle between the long axis of the tooth and the occlusal plane (angle $\delta$ ) measured on orthopantomography before and after orthodontic treatment

According to Artun [1], the average $\delta$ angle value for predictable eruption of maxillary third molar should be around $60^{\circ}$ at the moment when the tooth becomes closer to the place of eruption. Taking into consideration the fact that the upper third molar changes physiologically its inclination during dental arch development, we studied the further influence of the orthodontic treatment upon third molar angulation. Changes in the mean third maxillary molars angulation in the extraction 
and non extraction group before and after orthodontic treatment are presented in table 2. Paired Sample T-test was applied to compare the mean difference between $\delta$ angles values at T1 and T2 (table 3 and table 4).

Table 2

THIRD MAXILLARY MOLAR ANGULATION IN RELATION WITH THE OCCLUSAL PLANE (ANGLE $\delta$ ) AT T1 AND T2

\begin{tabular}{|c|c|c|c|c|c|c|}
\hline & & $\mathrm{N}$ & Mean & Std. Deviation & \% of Total N & Std. Error of Mean \\
\hline \multirow{3}{*}{ Angle $\delta$ at T1 } & $\begin{array}{c}\text { Without } \\
\text { extractions }\end{array}$ & 148 & 69.4730 & 16.88983 & $71.15 \%$ & 1.96340 \\
\cline { 2 - 7 } & With extractions & 60 & 63.3571 & 16.54671 & $28.84 \%$ & 3.12703 \\
\cline { 2 - 7 } & Total & 208 & 67.7941 & 16.93806 & $100.0 \%$ & 1.67712 \\
\hline \multirow{2}{*}{ Angle $\delta$ at T2 } & $\begin{array}{c}\text { Without } \\
\text { extractions }\end{array}$ & 148 & 71.247 & 18.0302 & $71.15 \%$ & 2.0034 \\
\cline { 2 - 7 } & With extractions & 60 & 66.100 & 37.9349 & $28.84 \%$ & 6.9259 \\
\cline { 2 - 7 } & Total & 208 & 69.856 & 24.9216 & $100.0 \%$ & 2.3655 \\
\hline
\end{tabular}

Table 3

PAIRED SAMPLE T-TEST FOR ANGLE $\delta$ VALUES AT T1 AND T2 IN THE NON EXTRACTION GROUP

\begin{tabular}{|c|c|c|c|c|c|c|c|c|}
\hline & \multicolumn{5}{|c|}{ Paired Differences } & \multirow[t]{3}{*}{$\mathrm{t}$} & \multirow[t]{3}{*}{$\mathrm{df}$} & \multirow{3}{*}{$\begin{array}{l}\text { Sig. (2- } \\
\text { tailed) }\end{array}$} \\
\hline & \multirow[t]{2}{*}{ Mean } & \multirow[t]{2}{*}{$\begin{array}{c}\text { Std. } \\
\text { Deviation }\end{array}$} & \multirow[t]{2}{*}{$\begin{array}{c}\text { Std. Error } \\
\text { Mean }\end{array}$} & \multicolumn{2}{|c|}{$\begin{array}{l}\text { 95\% Confidence Interval of the } \\
\text { Difference }\end{array}$} & & & \\
\hline & & & & Upper & Lower & & & \\
\hline Angle $\delta$ & $\begin{array}{c}- \\
2.18919\end{array}$ & 12.85501 & 1.49437 & -5.16745 & .78908 & -1.465 & 73 & .147 \\
\hline
\end{tabular}

Table 4

PAIRED SAMPLE T-TEST FOR ANGLE $\delta$ IN THE EXTRACTION SAMPLE AT T1 AND T2

\begin{tabular}{|c|c|c|c|c|c|c|c|c|}
\hline & \multicolumn{5}{|c|}{ Paired Differences } & \multirow[t]{3}{*}{$\mathrm{t}$} & \multirow[t]{3}{*}{$\overline{d f}$} & \multirow{3}{*}{$\begin{array}{l}\text { Sig. }(2- \\
\text { tailed) }\end{array}$} \\
\hline & \multirow[t]{2}{*}{ Mean } & \multirow[t]{2}{*}{$\begin{array}{c}\text { Std. } \\
\text { Deviation }\end{array}$} & \multirow[t]{2}{*}{$\begin{array}{l}\text { Std. Error } \\
\text { Mean }\end{array}$} & \multicolumn{2}{|c|}{$\begin{array}{l}\text { 95\% Confidence Interval of the } \\
\text { Difference }\end{array}$} & & & \\
\hline & & & & Upper & Lower & & & \\
\hline Angle $\delta$ & -1.39286 & 40.90852 & 7.73098 & -17.25552 & 14.46981 & -.180 & 27 & .858 \\
\hline
\end{tabular}

The mean values for third maxillary molar inclination in relation to the occlusal plane (table2) recorded a similar increase in both extraction and non extraction group between $\mathrm{T} 1$ and T2; in the non extraction group angle $\delta$ increased at the end of the orthodontic treatment from $69.47^{\circ}(\mathrm{SD}=16.88)$ at $\mathrm{T} 1$ to $71.24^{\circ}(\mathrm{SD}=18.03)$ at $\mathrm{T} 2$, while in the first maxillary extraction sample the increase was from the initial value of $63.35^{\circ}(\mathrm{SD}=16.54)$ to $66.10^{\circ}(\mathrm{SD}=37.93)$ with a greater range of improvement of third maxillary molar angulation in the last group.

In both Paired Sample T-test used to compare the values for $\delta$ angle inside each sample at T1 and T2 Sig.> 0.05 and we concluded that there are no significant statistic differences between third maxillary molar angulation and the occlusal plane before and after orthodontic treatment, neither in the non extraction sample, nor in the extraction group. Considering these findings we may use $\delta$ angle as a secondary prediction factor for third upper molar eruption or impaction.

The angle between the long axes of the third and second maxillary molars (angle $\theta$ ) measured on orthopantomography before (T1) and after orthodontic treatment (T2)

In the non extraction sample the mean values for angle $\theta$ decreased with a small extent between $\mathrm{T} 1$ and $\mathrm{T} 2$ from $16.52^{\circ}$ $(\mathrm{SD}=14.00)$ to $14.01^{\circ}(\mathrm{SD}=11.54)$, mostly due to the normal intra bone mesial rotation of the maxillary third molar. In the extraction sample angle $\theta$ decreased from mean value of $20.10^{\circ}(\mathrm{SD}=16.21)$ at $\mathrm{T} 1$ to $15.60^{\circ}(\mathrm{SD}=14.06)$ at $\mathrm{T} 2$, with a more accelerated movement of the third maxillary molar after first premolar removal. Paired Sample T-Test was applied for angle $\theta$ in the non extraction group (table 5) and for the premolar extraction sample (table 6). 
Table 5

PAIRED SAMPLE T-TEST FOR ANGLE $\theta$ AT T1 AND T2 IN THE NON EXTRACTION SAMPLE

\begin{tabular}{|c|c|c|c|c|c|c|c|c|}
\hline & \multicolumn{5}{|c|}{ Paired Differences } & \multirow[t]{3}{*}{$\mathrm{t}$} & \multirow[t]{3}{*}{ df } & \multirow{3}{*}{$\begin{array}{l}\text { Sig. }(2- \\
\text { tailed) }\end{array}$} \\
\hline & \multirow[t]{2}{*}{ Mean } & \multirow[t]{2}{*}{$\begin{array}{c}\text { Std. } \\
\text { Deviation }\end{array}$} & \multirow[t]{2}{*}{$\begin{array}{l}\text { Std. Error } \\
\text { Mean }\end{array}$} & \multicolumn{2}{|c|}{$\begin{array}{l}\text { 95\% Confidence Interval of } \\
\text { the Difference }\end{array}$} & & & \\
\hline & & & & Upper & Lower & & & \\
\hline $\begin{array}{c}\text { Angle } \theta \\
\text { T1/T2 }\end{array}$ & 2.5135 & 12.1150 & 1.4083 & -.2933 & 5.3203 & 1.785 & 73 & .078 \\
\hline
\end{tabular}

Table 6

PAIRED SAMPLE T-TEST FOR ANGLE $\theta$ AT T1 AND T2 IN THE EXTRACTION SAMPLE

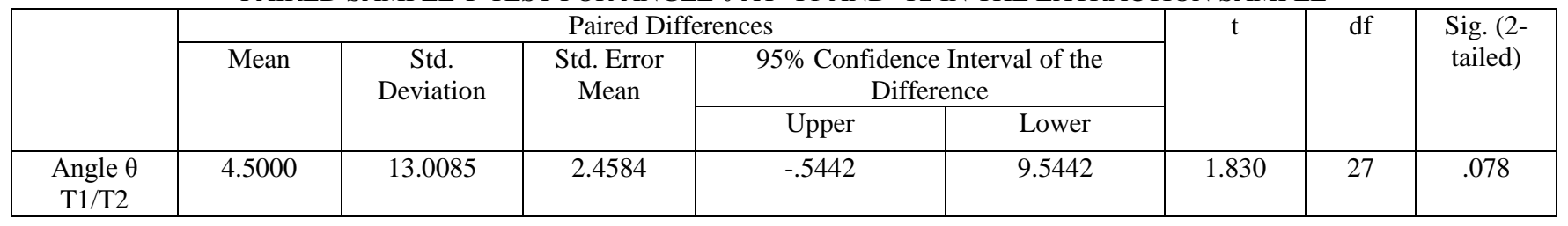

For both samples Paired T-test found Sig=.078, greater than 5\%, which means that there is no statistical significant correlation between changes in third maxillary molar angulation related to the second upper molar no matter if the orthodontic treatment is carried out with or without premolar extraction.

Third maxillary molar assessment at the beginning and at the end of the orthodontic treatment concerning the probability of eruption or impaction can be done easily on panoramic films either by linear or angular measurements [18,19]. According to Artun [20] the most important predictive parameter is the size of the retromolar space related to the mesio-distal diameter of the upper third molar. Insufficient posterior space at the beginning of the orthodontic treatment and, more important, at the end of the orthodontic treatment will lead to tooth impaction. Of course, during treatment mesial movement of the maxillary molars can increase to some extent the retromolar space, while class II mechanics by distal movement of the maxillary dentition will reduce third molar chances for proper eruption [21]. Many studies reported that first premolar extraction by orthodontic reasons facilitates maxillary third molar eruption by creating additional space in the posterior area; but in cases where there is a severe lack of space even premolar extraction does not provide the space conditions required for eruption [22].

In our study carried out on orthopantomograms of 104 orthodontic patients, 74 with non extraction orthodontic treatment and 30 with extraction of bilateral upper premolars, we used the ratio between the posterior available space and the mesio distal diameter of the maxillary third molar. A ratio less than 1was considered to be with high risk of impaction unless additional space is provided, equal to 1 uncertain, depending on the type of treatment and more than 1 with great chances for eruption. Our statistics confirmed the previous studies $[23,24]$ where is reported that during the non extraction treatment we gain very little posterior space, so the initial prognosis usually remains relative the same. On the other side, first premolar extraction increases almost 4 times the number of third maxillary molars with favorable space condition for eruption as it is described in literature. In the extraction sample the number of teeth where the space ratio is less than 1 decreased by the same amount, while the percent with ratio equal to 1 remained relative stable.

Third molar angulation in relation with the occlusal plane can be used also an indicator for eruption or impaction. Kim [25] considers that an angle less than $30^{\circ}$ between third upper molar long axis and the occlusal plane at the end of the treatment is an indicator for distal impaction and more than $90^{\circ}$ for mesial impaction of the upper third molar. Our study showed no statistically significant changes in third molar angulation with the occlusal plane during orthodontic treatment with or without premolar extractions. These findings are related to those of other researchers who reported that orthodontic treatment has less or no influence more than the physiologic rotational movement of the third molar bud. This is an indication that this angle has predictive value from the beginning of the treatment.

The angle between the long axes of the third and upper molar measured on orthopantomogram was considered before and after orthodontic treatment to check if there are any statistic significant changes in its angulation. In both samples, with or without extraction of upper first premolars, we noticed the uprighting of the tooth during orthodontic treatment with approximately the same amount $\left(2-3^{\circ}\right)$, but with no statistical significance revealed by Paired Sample T-test. Our findings are similar to those reported by Gohilot [26] who suggested that maxillary third molar position at the end of the treatment is more related to the initial angulation and type of orthodontic mechanics used than to first premolar extraction.

In the extraction cases our studies showed that there is a great potential for third maxillary molar eruption and all practitioners should be informed about this opportunity. There is a general concern regarding the vulnerability of the wisdom teeth to decay due to its posterior position in the dental arch; new prophylactic approaches are now available like fluoride sealants and varnishes, and they are indicated to be applied after third maxillary molar eruption [27,28].

\section{Conclusions}


The decision regarding the third maxillary molar can be taken at the beginning or at the end of the treatment. Orthodontic treatment plans that involve heavy class II elastics, strong anchorage or distal movement of the maxillary dentition should considered the enucleation of the upper maxillary treatment at the beginning, during or at the end of the therapy. Depending on the available posterior space or angulation, the third maxillary molar prediction for impaction or eruption can be assessed in many cases before starting a non extraction orthodontic treatment because there is little influence on the posterior area. The extraction of bilateral maxillary premolars brings substantial improvement in the available posterior space, but has limited influence upon third molar angulation.

\section{References}

1.ARTUN J.,THALIB L., LITTLE RM, European Journal of Orthodontics, 2005, 27, p. 590-596.

2.BJÖRK A., JENSEN E., PALLING M., Acta Odontol Scand., 1956, 14, p.231-272

3.BJORK A., J Dent Res., 1963, 42, p.400-411

4.SAYSEL M.Y., MERAL G.D., KOCADERELI I., TASAR F., The Angle Orthodontist, 2005, 75,no. 5, p.719-722

5.JUNG Y.H., CHO B.H., Imaging Science in Dentistry, 2015, 45, p. 234-240

6.MIHAI AM, LULACHE IR, GRIGORE R, SANABIL AS, BOIANGIU S, IONESCU E., Journal of Medicine and Life, 2013,6, p.171-175

7.BAYRAM M., OZER M., ARICI S., Oral Surg Oral Med Oral Pathol Oral RadiolEndod, 2009, 107 no. 2, p. 14-20

8.JANSON G., PUTRICK L.M., HENRIQUES J.F., DE FREITAS M.R., HENRIQUES RP, Eur. J. Orthod., 2006, 28, no. 6, p. 573-579

9.BRIGNARDELLO-PETERSEN R, J Am Dent Assoc, 2017 Aug, 148, no. 8, p. 119

10.MICLOTTE A, GROMMEN B, CADENAS de LLANO-PERULA M., VERDONCK A., JACOBS R., WILLEMS G., J Dent, 2017 Jun, 61, p. 55-66

11.ALMPANI K., KOLOKITHA O.E., World Journal of Clinical Cases, 2015, 3, p. 132-140

12.KANDASAMY S., RINCHUSE D.J., Australian Dental Journal, 2009, 54, pp. 284-292

13.SEBBAR M., BOURZGUI F., Rev Stomatol Chir Maxillofac, 2011 Nov, 112, no. 5, 263-8

14.ELSEY M.J., ROCK W.P., Br J Oral Maxillofac Surg, 2000 Aug, 38, no. 4, 350-3

15.BADAWI FAYAD J., LEVY J.C., YAZBECK C., CAVEZIAN R., CABANIS, Am J OrthodDentofac Orthop, 2004 Feb, 125, no. 2, 200-2

16.MURARIU A., BOBU L., FORNA N., IORDAN A., ZELINSCHI D., BICIUSCA R., IORDACHE C., Romanian Journal of Oral Rehabilitation, 2019, 11, no.3, 99-107

17.MURARIU A., FORNA D.A., MANOLACHE F., Forna N.C., Romanian Journal of Oral Rehabilitation, 9, no. 3, 48-54

18.SCHULZE R., KRUMMENAUER F., SCHALLDACH F., D'HOEDT B.,Dentomaxillofacial Radiology, 2000, 29, p. 52-56

19.STRAMOTAS S., GEENTY J.P.,PETOCZ P., DARENDELILER M.A., European Journal of Orthodontics, 2002, 2, p. $43-52$

20.ARTUN J., BEHBEHANI F., THALIB L., Angle Orthod, 2005 Nov, 75, no. 6, p. 904-11

21.KAMALAKANNAN D, ANATHANARAYANAN V, PADMANABAN S, Indian J Dent Res., 2019 May-Jun,30, no.3, p. 428-436

22.UTHMAN AT, Oral Surg Oral Med Oral Pathol Oral Radiol Endod, 2007 Oct, 104, no. 4,p. 76-82

23.HYAM D.M., Australian Dental Journal, 2018, 63, no.1, 19-26

24.YIGIT M., GOKCE D., KOCADERELI I., TASAR F., Angle Orthod ,2005, 7, p. 719-722

25.KIM T.W., ARTUN J., BEHBEHANI F., ARTESE F., Am J OrthodDentofacial Orthop, 2003, 123, p. 138-145

26.GOHILOT A., PRADHAN T., KELUSKAR K.M., J Oral Biol Craniofacial Res. 2012, 2, p. 97-104

27.SAVEANU C.I., CONSTANTIN O., DANILA C., DANILA V., ANISTOROAEI D.,Mat. Plast., 53, no. 4, p. $653-656$

28.SAVEANU C.I., FORNA N.C., DANILA I, BARLEAN L., BALCOS C., DANILA V., GOLOVCENCU L., ANISTOROAEI D., Romanian Journal of Oral Rehabilitation, 10, no. 4, p. 149-156

Manuscript received: 26.11 .2019 